\title{
Large eddy simulations of differential molecular diffusion in non-reacting turbulent jets of $\mathrm{H}_{2} / \mathrm{CO}_{2}$ mixing with air
}

\author{
G. Maragkos, ${ }^{1}$ P. Rauwoens, ${ }^{2}$ D. Fauconnier, ${ }^{1}$ and B. Merci ${ }^{1}$ \\ 1) Department of Flow, Heat and Combustion Mechanics, Ghent University, B-9000, \\ Belgium \\ ${ }^{2)}$ Department of Civil Engineering, Ghent University, B-9052,

\section{Belgium}

(Dated: 4 April 2014)

Large eddy simulations of non-reacting $\mathrm{H}_{2} / \mathrm{CO}_{2}$ jets mixing with air are performed and the calculations are compared with the experiments reported by Smith et al. (1995). The influence of differential diffusion effects for Reynolds numbers $R e=$ $1000-8000$ is analyzed and a differential diffusion parameter, $\xi$, is defined on the basis of normalized $\mathrm{H}_{2}$ and $\mathrm{CO}_{2}$ concentrations in order to quantify the effects of differential diffusion with increasing Reynolds number. The analysis is made not only in physical space but also with scatter plots and histograms. The simulation results reveal that differential diffusion effects are significant at downstream locations (more than 15 nozzle diameters away from the inlet) only for the lower Reynolds numbers $(R e=1000-2000)$. However, differential diffusion effects are present for all Reynolds numbers examined close to the inlet (closer than 10 nozzle diameters). This is confirmed by the mean results of the differential diffusion parameter, $\xi$, but also by looking at the histograms of $\xi$. This is an important indication that differential diffusion can be important in turbulent reacting flows if laminarization of the flow or weakening of turbulent diffusion occurs. Including differential diffusion effects in turbulent reactive flows involving mixtures with vastly different mass diffusivities can, therefore, improve the accuracy of numerical simulations. Results obtained assuming equal species mass diffusivities revealed that differential diffusion effects do not have any significant influence in the velocity field. 


\section{INTRODUCTION}

Numerical simulations of turbulent combustion usually employ the assumption that every chemical component diffuses in the same manner, i.e. has the same mass diffusivity in the mixture. In case of fossil fuel this assumption is reasonable. However, it is well know that in the case of hydrogen combustion, this assumption is no longer valid, since $\mathrm{H}_{2}$, as a light molecule, diffuses more rapidly than other chemical components. In addition, in many turbulent combustion applications the high heat release rates can cause a local laminarization of the flow and then the effects of molecular differential diffusion can become significant for both moderate ${ }^{1-4}$ and high ${ }^{5,6}$ Reynolds numbers. This can have a strong effect in reacting flows where accurate prediction of species concentrations is of great importance ${ }^{7}$ since they are a prerequisite for accurately predicting the local temperatures ${ }^{8-10}$, chemical reaction rates and pollutant concentrations ${ }^{11-13}$. Mostly, differential diffusion effects are ignored when performing numerical simulations of turbulent combustion because it either leads to great modelling simplifications (use of the mixture fraction approach) or because it is expected that turbulent mixing is a far more dominant process than molecular mixing so that the turbulent diffusivity is an order of magnitude larger than the molecular diffusivity.

Several experimental and numerical papers studying the effects of differential diffusion in non-reacting cases exist. Dibble and Long ${ }^{12}$ reported two-dimensional measurements of differential diffusion of the same flow while Bilger and Dibble ${ }^{14}$ performed experiments in a non-reacting hydrogen-propane jet flowing into air. Long et al. ${ }^{15}$ presented a different approach, compared to Bilger and Dibble, to study differential diffusion using Planar LaserInduced Fluorescence (PLIF) and Lorenz-Mie scattering techniques. Lavertu et al. ${ }^{16}$ studied the effects of differential diffusion in high Schmidt number jets and Saylor and Sreenivasan ${ }^{17}$ on low Reynolds number water jets. Several experimental studies exist on the dependence of differential diffusion on Reynolds number ${ }^{18,19}$, while direct numerical simulations (DNS) studying differential diffusion in isotropic turbulence have also been reported ${ }^{20-28}$.

The goal of this study is two-fold: First, to model the effects of differential diffusion in the mixing of non-reacting turbulent jets and to quantify the relative influence of these effects, at various downstream locations, with increasing Reynolds numbers. Second, to examine the validity of the typical assumption made in turbulent flows of neglecting differential diffusion effects and to investigate any potential implications of this assumption in turbulent reacting 
flows. We consider in this work non-reacting jets, in order to avoid uncertainties due to combustion modelling. In concreto, we perform various large eddy simulations (LES) of a non-reacting turbulent $\mathrm{H}_{2} / \mathrm{CO}_{2}$ jets mixing with air. Contrary to previous studies, the influence of differential diffusion will be examined over a wide range of downstream locations from the inlet $(\mathrm{x} / \mathrm{d}=5,15,30)$ and for a wide range of Reynolds numbers $(\mathrm{Re}=1000-8000)$. It is worth to note that many previous studies have not examined the influence of differential diffusion close to the inlet for moderate Reynolds numbers. In addition, there are not many other LES studies, in total, reporting on the influence of differential diffusion, where numerical results have been presented with and without differential diffusion effects.

The experiments conducted in the Turbulent Diffusion Flames (TDF) laboratory at Sandia National Laboratories and reported by Smith et al. ${ }^{18}$, are considered here. The current numerical study is inspired by this experimental work for the following reasons. First of all, it is a jet configuration, which is a representative configuration for practical flames. Secondly, the $\mathrm{H}_{2}$ concentration in the mixture ( $36 \%$ by volume) is high, so that the effects of differential diffusion can be easily identified. Third, the experiments were performed for a wide range of Reynolds numbers, spanning from very low $(R e=1000)$ to really high $(R e=64000)$, providing this way a clear relationship between differential diffusion and increasing Reynolds number. To the authors' best knowledge no other numerical studies on this experimental case have appeared in the literature. However, the amount of experimental data reported was limited (no velocity field measurements or species concentrations were reported) and the comparison with the simulation results will be made to the degree that this is possible.

\section{GOVERNING EQUATIONS}

We use a modified version of FireFOAM 1.6 (http://code.google.com/p/firefoam-dev/) that has already been successfully applied in previous numerical studies ${ }^{29-31}$. The modifications made in the original implementation of FireFOAM 1.6 include:

- Elimination of enthalpy equation.

- Replacement of mixture fraction equation by an equation for chemical species.

- Calculation of mixture viscosity as a linear combination of the species viscosities in- 
stead of being constant or temperature dependant.

- Calculation of mixture density as a linear combination of the species densities instead of using the ideal gas law.

The code solves for the low-Mach number form of the Navier-Stokes equations, using Favre-filtered quantities $(\widetilde{\phi}=\overline{\rho \phi} / \bar{\rho})$, along with transport equations for species mass fractions for a non-reacting, isothermal system. The filtered transport equations for mass, momentum and chemical species read:

$$
\begin{gathered}
\frac{\partial \bar{\rho}}{\partial t}+\frac{\partial \bar{\rho} \widetilde{u}_{i}}{\partial x_{i}}=0 \\
\frac{\partial \bar{\rho} \widetilde{u}_{j}}{\partial t}+\frac{\partial \bar{\rho} \widetilde{u}_{i} \widetilde{u}_{j}}{\partial x_{i}}=-\frac{\partial \bar{p}}{\partial x_{j}}+\frac{\partial \bar{\tau}_{i j}}{\partial x_{i}}+\frac{\partial \bar{\tau}_{i j}^{s g s}}{\partial x_{i}}+\bar{\rho} g_{j}, \quad j=1,2,3 \\
\frac{\partial \bar{\rho} \widetilde{Y}_{k}}{\partial t}+\frac{\partial \bar{\rho} \widetilde{u}_{i} \widetilde{Y}_{k}}{\partial x_{i}}=-\frac{\partial \bar{j}_{i k}}{\partial x_{i}}-\frac{\partial \bar{j}_{i k}^{s g s}}{\partial x_{i}}, \quad k=1, \ldots, N_{s}-1
\end{gathered}
$$

where $\bar{\rho}$ is the mixture density, $\widetilde{u}$ is the velocity, $\bar{p}$ is the pressure, $\widetilde{Y}_{k}$ is the species mass fraction and $N_{s}$ is the number of species. The viscous stress tensor, $\bar{\tau}_{i j}$, is modeled by Newton's law, in terms of resolved quantities:

$$
\bar{\tau}_{i j}=\mu\left(\frac{\partial \widetilde{u}_{i}}{\partial x_{j}}+\frac{\partial \widetilde{u}_{j}}{\partial x_{i}}\right)-\frac{2}{3} \mu \frac{\partial \widetilde{u}_{k}}{\partial x_{k}} \delta_{i j}
$$

where $\delta_{i j}$ is the Kronecker symbol.

The laminar viscosity of the mixture, $\mu$, is calculated as a linear function of the species individual viscosities as:

$$
\mu=\sum \mu_{k} \bar{X}_{k}
$$

where $\bar{X}_{k}$ is the species mole fraction.

The widely used standard Smagorinsky model ${ }^{32}$ is used for closure of the sub-grid scale stress terms in the momentum equations. It is an eddy viscosity type model where the unresolved sub-grid scale (SGS) stress terms, $\bar{\tau}_{i j}^{\text {sgs }}$, are expressed according to the Boussinesq assumption as:

$$
\bar{\tau}_{i j}^{s g s}+\frac{1}{3} \bar{\rho} \delta_{i j} \tau_{k k}=\mu_{t}\left(\frac{\partial \widetilde{u}_{i}}{\partial x_{j}}+\frac{\partial \widetilde{u}_{j}}{\partial x_{i}}\right)=2 \mu_{t} \bar{S}_{i j}
$$

where $\bar{S}_{i j}$ is the strain rate tensor component. The turbulent viscosity, $\mu_{t}$, is modelled as:

$$
\mu_{t}=\bar{\rho}\left(c_{s} \Delta\right)^{2}|\bar{S}|
$$


where $\Delta$ is the filter size, taken to be $\Delta=(\Delta x \Delta y \Delta z)^{\frac{1}{3}}$, with $\Delta x, \Delta y$ and $\Delta z$ the effective grid mesh spacings and $\bar{S}$ is the strain rate, $\bar{S}=\left(2 \bar{S}_{i j} \bar{S}_{i j}\right)^{0.5}$. A Smagorinsky constant of $c_{s}=0.1$ is used in this study ${ }^{33-35}$.

The un-resolved sub-grid scale species fluxes, $\bar{j}_{i k}^{s g s}$, in the species equation are modeled by the gradient diffusion hypothesis model as:

$$
\bar{j}_{i k}^{s g s}=-\frac{\mu_{t}}{S c_{t}} \frac{\partial \widetilde{Y}_{k}}{\partial x_{i}}
$$

assuming a constant turbulent Schmidt number of $S c_{t}=0.5$. A sensitivity study on this value $\left(S c_{t}=0.5,0.7,1.0\right)$, not shown here, did not reveal any significant influence of this parameter on the simulation results (maximum deviation in the species mass fraction of less than $4 \%)$.

The total diffusion velocities, $\widetilde{V}_{i k}$, in the species flux, $\bar{j}_{i k}=\bar{\rho} \widetilde{Y}_{k} \widetilde{V}_{i k}$, are expressed as:

$$
\widetilde{V}_{i k}=\widetilde{V}_{i k}^{D}+\widetilde{V}_{i}^{C}
$$

where the ordinary diffusion velocities, $\widetilde{V}_{i k}^{D}$, in the absence of pressure gradients and external forces, are approximated by Fick's law as:

$$
\widetilde{V}_{i k}^{D} \approx-\frac{D_{k}}{\widetilde{Y}_{k}} \frac{\partial \widetilde{Y}_{k}}{\partial x_{i}}
$$

and the correction velocity, $\widetilde{V}_{i}^{C}$, is determined from the mass conservation constraint, $\sum_{k=1}^{N_{s}} \bar{j}_{i k}=0$, as:

$$
\widetilde{V}_{i}^{C}=\sum_{k=1}^{N_{s}} \widetilde{Y}_{k} \widetilde{V}_{i k}=-\sum_{k=1}^{N_{s}} D_{k} \frac{\partial \widetilde{Y}_{k}}{\partial x_{i}}
$$

The species mass diffusion coefficients, $D_{k}$, are calculated as:

$$
D_{k}=\frac{\mu}{\rho S c_{k}}
$$

where $S c_{k}$ is a constant Schmidt number of species $k$.

The mixture density is calculated as a linear function of the individual species densities as:

$$
\bar{\rho}=\sum \rho_{k} \bar{X}_{k}
$$

where $\rho_{k}$ is the species density, calculated by the ideal gas law. 


\section{NUMERICAL SET-UP}

The case consists of non-reacting turbulent jets of $36 \% \mathrm{H}_{2}$ and $64 \% \mathrm{CO}_{2}$ (by volume), issued into air from a round tube with inner diameter $d=7.7 \mathrm{~mm}$. The simulations are performed on a cylindrical mesh, $10 \mathrm{~d} \times 35 \mathrm{~d}$, with a rectangular grid in the central region $(2 \mathrm{~mm} \times 2 \mathrm{~mm})$. The inflow of the $\mathrm{H}_{2} / \mathrm{CO}_{2}$ mixture is located in the center of the bottom plane. The grid resolution for the inlet patch is set to $6 \times 6$ cells (rectangular) and $8 \times 32$ (cylindrical), resulting in 18 cells across the inlet. Outside the inlet patch, 40 cells were used radially (compressed towards the inlet). In the axial direction 400 cells are used. The total number of cells is then 0.456 million cells, resulting in a minimum and maximum grid spacing of $0.46 \mathrm{~mm}$ and $2.55 \mathrm{~mm}$.

A fixed inlet velocity, $u_{\text {inlet }}$, is applied to the inlet patch, according to the average inlet Reynolds number reported in the experiments. In the simulations, only the range $u_{\text {inlet }}=1.7-13.6 \mathrm{~m} / \mathrm{s}(R e=1000-8000)$ is considered. In the bottom plane of the domain $(y=0 \mathrm{~m})$ outside the tube, a fixed streamwise co-flow velocity $u_{c o-f l o w}=1.5 \mathrm{~m} / \mathrm{s}$ is imposed. The thickness of the tube is negligible. A mixed boundary condition (pressureInletOutletVelocity) is assigned for velocity at the sides of the domain and a Dirichlet boundary condition (totalPressure) for pressure. For the top (outlet) plane a mixed boundary condition (inletOutlet) is used for velocity and a Neumann boundary condition (zeroGradient) for pressure. The inlet boundary conditions for the mass fractions of $\mathrm{H}_{2}$ and $\mathrm{CO}_{2}$ are of Dirichlet type and set to uniform values (fixedValue).

In order to reproduce the break up of the jet core reported in the experiments, turbulence must be generated at the inlet. In this case, the axial inlet velocity component is excited with azimuthal forcing of the form proposed by Menon and Rizk ${ }^{39}$ :

$$
u^{\prime}=A u_{\text {inlet }} \sum_{n=1}^{N} \sin (2 \pi f t / n+\theta)
$$

where $A$ is the amplitude of forcing, $N$ is the number of modes (set to 6), $t$ is the time and $\theta$ the polar azimuthal angle. The frequency, $f$, is calculated from a corresponding Strouhal number of $0.3^{35}$. In the present simulations a relatively high level of forcing is used with an amplitude of $20 \%$ of the mean axial velocity. No forcing is applied to the other two velocity components. This method has already been used in previous numerical studies of jets ${ }^{35}$.

The governing equations are advanced in time using a first order implicit 'Euler' scheme. 
A variable time step is used in the simulations, setting the maximum Courant number to $C o=0.5$. All quantities are assigned to the cell centers (collocated grid) with velocities linearly interpolated to the cell faces. The convective terms are second order centrally differenced using 'Gauss linear' interpolation. For scalar transport, the bounded second order TVD scheme 'limitedLinear' is used, while the diffusive terms are centrally differenced and corrected for the non orthogonality of the mesh with 'Gauss linear corrected'. A PISO algorithm is used for the pressure - velocity coupling with a Rhie-Chow interpolation to avoid odd-even decoupling. Data are collected when statistically-steady flow conditions have been reached in every case.

At every point in the domain, the composition of the gas phase corresponds to a mixture of $\mathrm{H}_{2}, \mathrm{CO}_{2}, \mathrm{O}_{2}$ and $\mathrm{N}_{2}$ with molecular weights $W_{\mathrm{H}_{2}}=2.016 \mathrm{~g} / \mathrm{mol}, W_{\mathrm{CO}_{2}}=44.01 \mathrm{~g} / \mathrm{mol}$, $W_{\mathrm{O}_{2}}=32.0 \mathrm{~g} / \mathrm{mol}$ and $W_{N_{2}}=28.013 \mathrm{~g} / \mathrm{mol}$, respectively. Ambient (inlet) temperature and pressure are $300 \mathrm{~K}$ and $101325 \mathrm{~Pa}$. Effects of buoyancy are negligible as the resulting Froude number, shown in Table I, is much higher than unity for all test cases.

TABLE I. Flow parameters at the inlet.

\begin{tabular}{ccccc}
\hline $\mathrm{d}(\mathrm{m})$ & $\mathrm{u}_{\text {inlet }}(\mathrm{m} / \mathrm{s})$ & $\mathrm{u}_{\text {co-flow }}(\mathrm{m} / \mathrm{s})$ & $R e=\frac{\rho u d}{\mu}$ & $F r=\frac{\rho u^{2}}{\Delta \rho g d}$ \\
\hline 0.0077 & $1.7-13.6$ & 1.5 & $1000-8000$ & $26-1685$ \\
\hline
\end{tabular}

\section{RESULTS}

\section{A. Instantaneous results}

In order to give a first global impression, Figures 1 - 2 present instantaneous plots of $\mathrm{H}_{2}$ mole fractions for Reynolds numbers $R e=1000-8000$ with and without equal species diffusivities. A clear evolution of the flow field from laminar ( $R e=1000-2000)$, to transition to turbulent $(R e=4000)$ to fully turbulent $(R e=8000)$ with increasing Re is observed (left to right). Larger $\mathrm{H}_{2}$ concentrations are evident, on the centerline and close to the inlet, in the case of equal species diffusivities for the lowest Reynolds number case $R e=1000$ indicating that molecular diffusion is more important in this case. As the Reynolds number increases $(R e=2000-8000)$, however, turbulent mixing becomes dominant. 


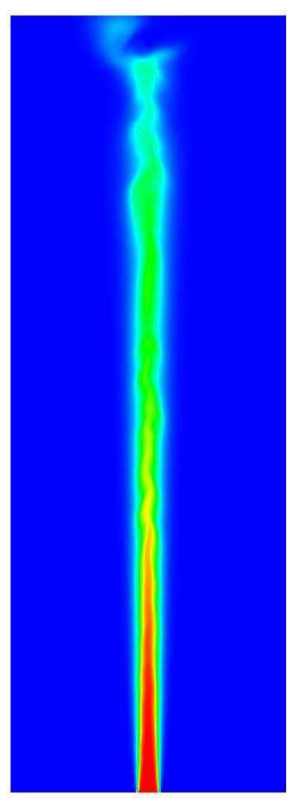

(a)

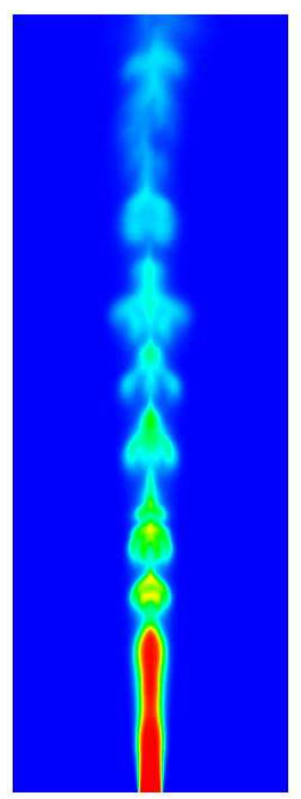

(b)

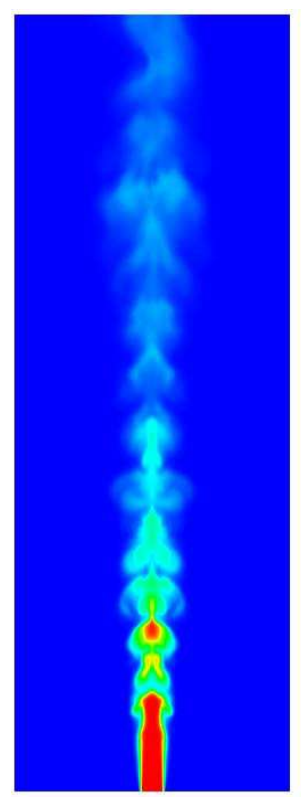

(c)

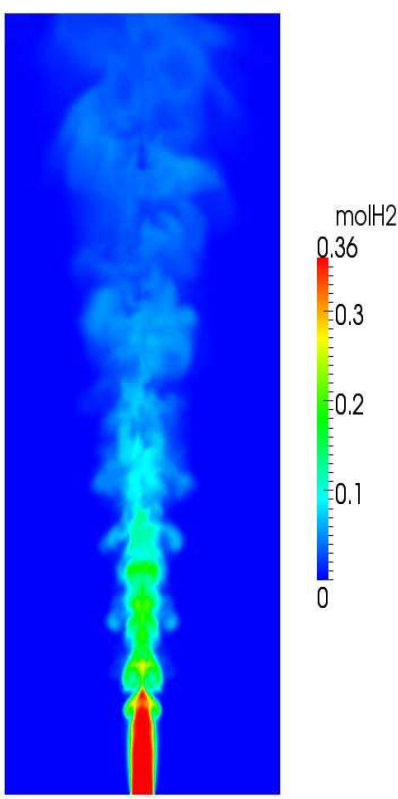

(d)

FIG. 1. Plots of instantaneous $\mathrm{H}_{2}$ mole fractions in a symmetry plane for (a) $R e=1000$, (b) $R e=2000,(\mathrm{c}) R e=4000$ and (d) $R e=8000$ with different diffusivities.

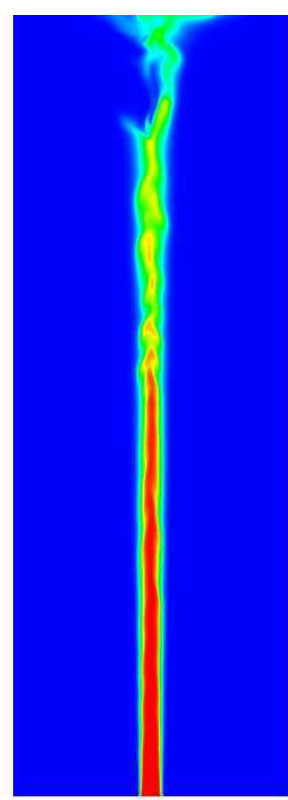

(a)

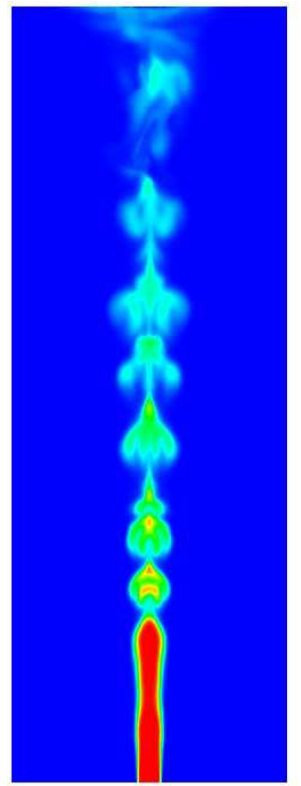

(b)

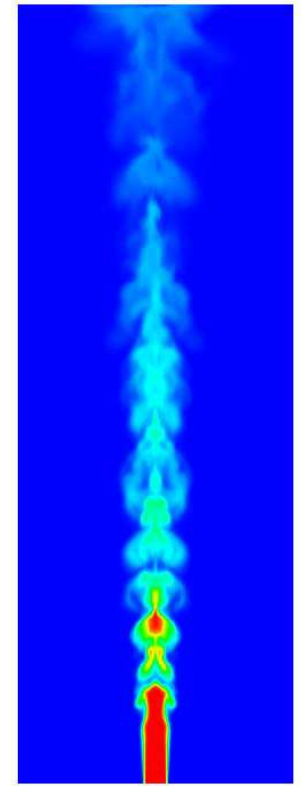

(c)

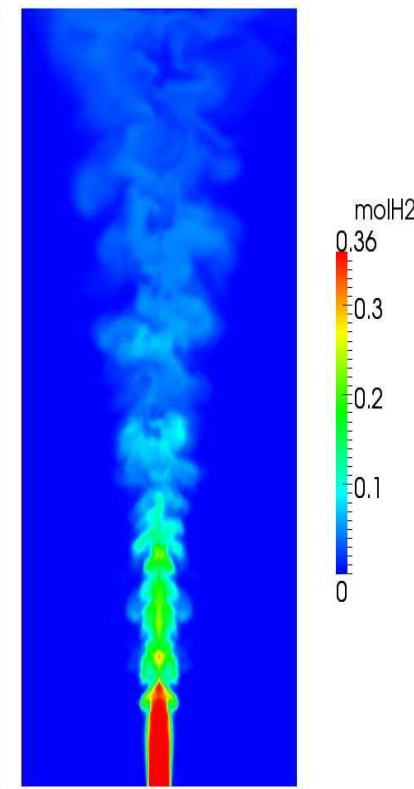

(d)

FIG. 2. Plots of instantaneous $\mathrm{H}_{2}$ mole fractions in a symmetry plane for (a) $R e=1000$, (b) $R e=2000,(\mathrm{c}) R e=4000$ and (d) $R e=8000$ with equal diffusivities. 
In order to have a quantitative measurement of differential diffusion, a differential diffusion parameter, $\xi$, is calculated as:

$$
\xi=\frac{\left[\mathrm{H}_{2}\right]-\left[\mathrm{H}_{2}\right]_{O}}{\left[\mathrm{H}_{2}\right]_{F}-\left[\mathrm{H}_{2}\right]_{O}}-\frac{\left[\mathrm{CO}_{2}\right]-\left[\mathrm{CO}_{2}\right]_{O}}{\left[\mathrm{CO}_{2}\right]_{F}-\left[\mathrm{CO}_{2}\right]_{O}}=\frac{\left[\mathrm{H}_{2}\right]}{\left[\mathrm{H}_{2}\right]_{F}}-\frac{\left[\mathrm{CO}_{2}\right]}{\left[\mathrm{CO}_{2}\right]_{F}}
$$

where $\left[\mathrm{H}_{2}\right]_{F}$ and $\left[\mathrm{CO}_{2}\right]_{F}$ are the 'fuel' stream mole fractions of $\mathrm{H}_{2}$ and $\mathrm{CO}_{2}$, and $\left[\mathrm{H}_{2}\right]_{O}$ and $\left[\mathrm{CO}_{2}\right]_{O}$ are the 'oxidizer' stream mole fractions of $\mathrm{H}_{2}$ and $\mathrm{CO}_{2}$, here to be taken zero. This definition of $\xi$, inspired by Bilger and Dibble ${ }^{14}$, takes on non-zero values only when the $\mathrm{H}_{2} / \mathrm{CO}_{2}$ ratio differs from its initial 'fuel' stream value. Other methods to quantify differential diffusion effects exist in the literature ${ }^{23,40}$, but in the present paper we adopt the one by Smith et al. ${ }^{18}$ so that the comparison with the experimental data is consistent.

Figure 3 presents instantaneous plots of the $\xi$ field for $R e=1000-8000$ (left to right). Clearly, differential diffusion effects become significantly smaller with increasing Reynolds number at downstream locations $(y / d>15)$. However, close to the inlet $(y / d<10)$ differential diffusion effects, remain present at the edge of the jet for all Reynolds number cases.

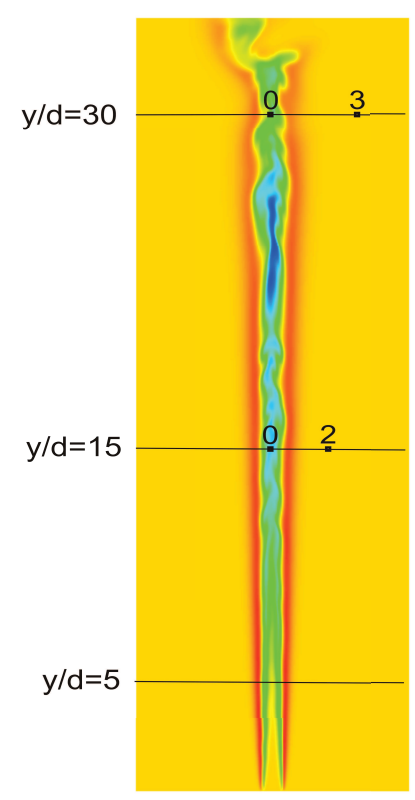

(a)

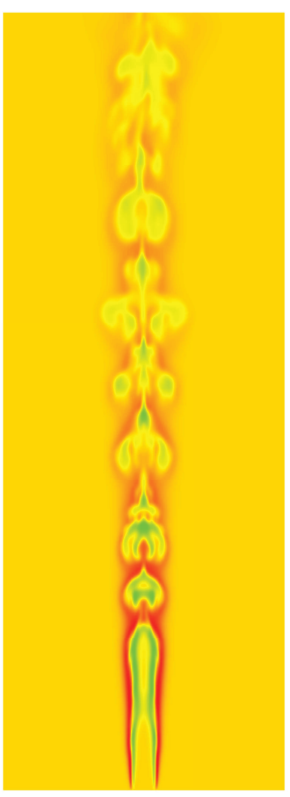

(b)

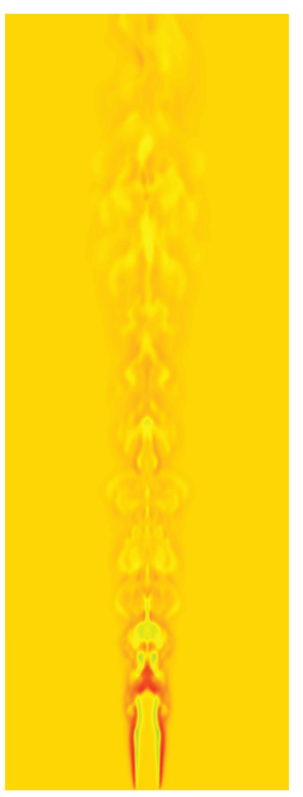

(c)

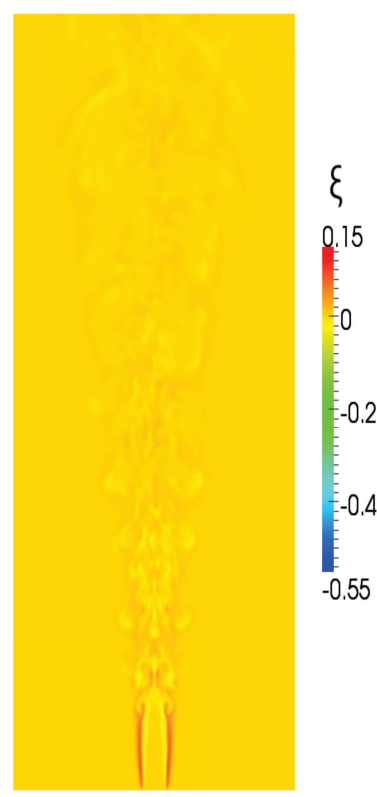

(d)

FIG. 3. Instantaneous plots of the differential diffusion parameter, $\xi$ (Eq. 15), for (a) $R e=1000$, (b) $R e=2000$, (c) $R e=4000$ and (d) $R e=8000$. Locations $y / d=5,15,30$ and radial distances $r / d=0,2,3$ are indicated (see below). 


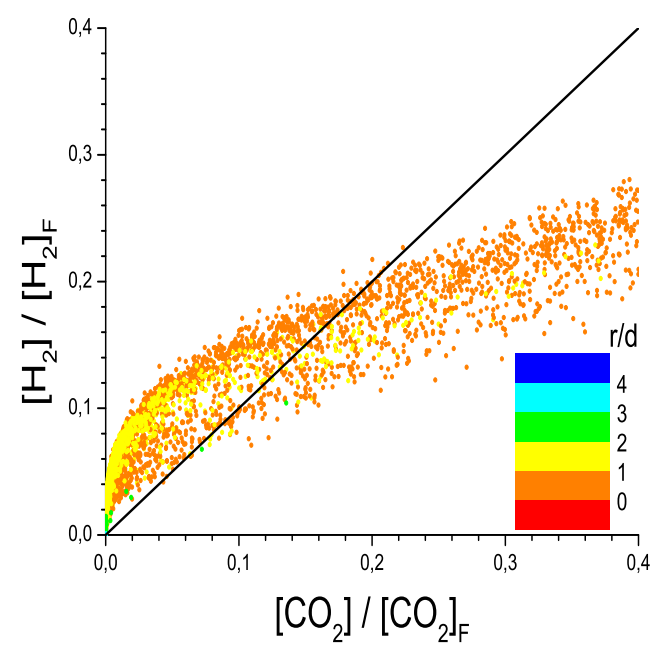

(a)

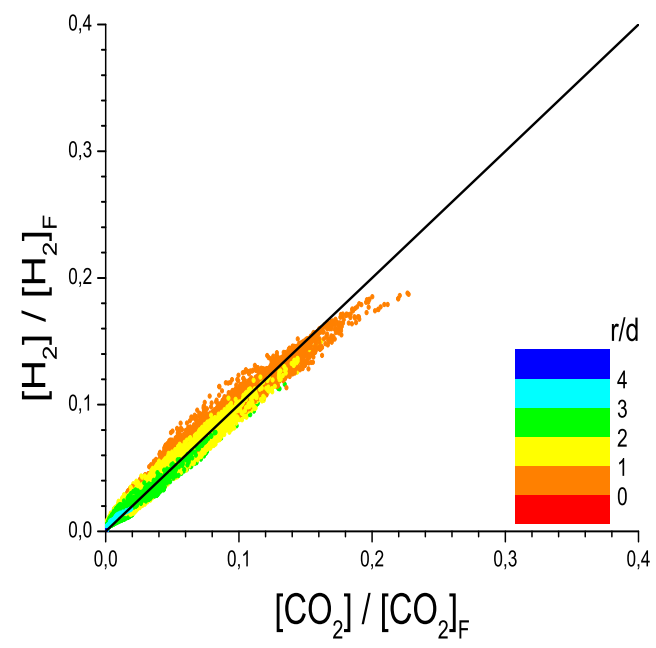

(c)

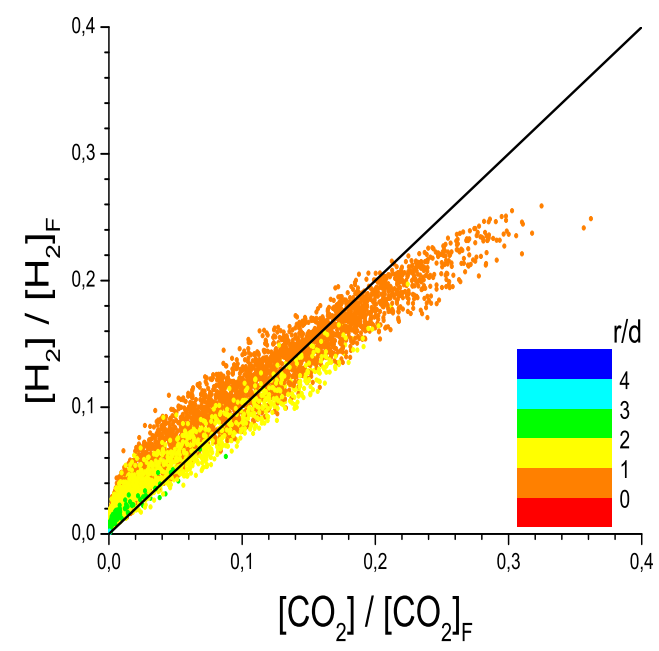

(b)

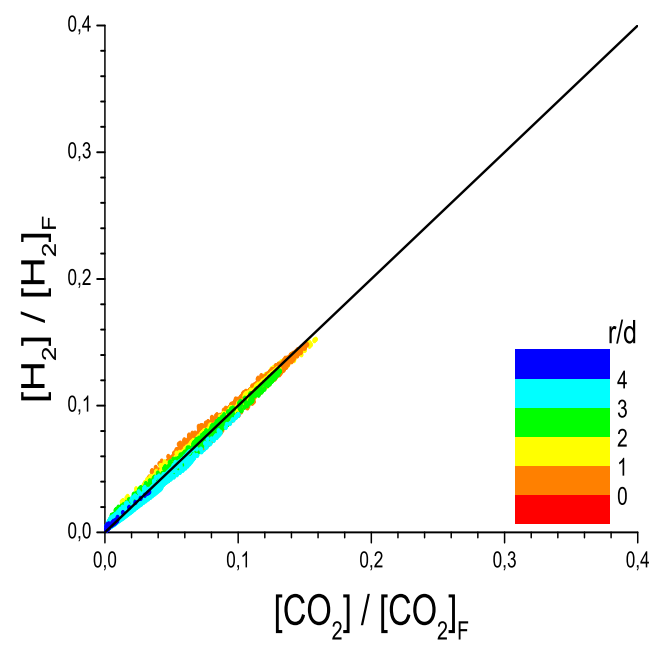

(d)

FIG. 4. Scatter plots of instantaneous $\mathrm{H}_{2}$ vs $\mathrm{CO}_{2}$ mole fractions at location $y / d=30$ for (a) $R e=1000,(\mathrm{~b}) R e=2000,(\mathrm{c}) R e=4000$ and (d) $R e=8000$.

\section{B. Scatter plots}

Figure 4 presents scatter plots of instantaneous $\mathrm{H}_{2}$ and $\mathrm{CO}_{2}$ mole fractions, normalized by their inlet value, at location $y / d=30$ for Reynolds numbers $R e=1000-8000$. Data from various radial locations have been used. The diagonal line represents the line of equal mixing, i.e. the line where the data points are when all species have the same mass diffusivity. The dispersion of points is clearly much wider for the lower Reynolds numbers. The points cluster around the equal diffusivity mixing line as Re is increasing, in line with the observations 
reported by Smith et al. ${ }^{18}$. For $R e=1000$, Figure 4(a), many points are observed both above and below the line of equal mixing. The points above the equal mixing line are located in off-axis locations and are due to the faster diffusivity of $\mathrm{H}_{2}$ from the central part of the jet towards to the outer edge. The points observed underneath the line of equal mixing are located around the jet axis, where $\mathrm{CO}_{2}$ concentrations are relatively larger. For $R e=2000$, Figure 4(b), the points cluster more around the line of equal mixing and the spreading of the jet increases (more green points are visible). Even though there are still points both above and below the line of equal mixing, the effect of differential diffusion has significantly decreased. For higher Reynolds numbers, Figures 4(c) - 4(d), the points follow the line of equal mixing closely. In this case, turbulent mixing is far more dominant than molecular diffusion. The range of values slightly increases with Re, since more mixture is injected, and thus higher concentrations are observed.

\section{Results for mean quantities}

Results obtained assuming equal mass diffusivities for all species revealed that differential diffusion did not have a significant effect on the velocity field (maximum deviation in the maximum streamwise velocity of less than $3 \%$ ) and are not presented in the paper.

Figures 5 - 8 present the mean $\mathrm{CO}_{2}$ and $\mathrm{H}_{2}$ mole fractions for Reynolds numbers $R e=$ $1000-8000$ at locations $y / d=15,30$ with and without equal species diffusivities. It is observed that with the equal diffusivity assumption, the $\mathrm{H}_{2}$ concentrations are about $40 \%$ larger for $R e=1000$ at locations $y / d=15,30$ (Figures $5(\mathrm{~b})-7(\mathrm{~b})$, respectively). This is indeed expected since, in this case, the diffusivity of $\mathrm{H}_{2}$ is much less than its actual value. For the rest of the test cases the differences remain relatively small.

The mean mole fractions of the $\mathrm{H}_{2} / \mathrm{CO}_{2}$ ratio at locations $y / d=5,15,30$ are plotted in Figure 9 for Reynolds numbers $R e=1000-8000$. The experimental data are also given for the $R e=1000-2000$ cases. A curved line is seen for $R e=1000$, indicating the case where the effects of differential diffusion are mostly evident. As the jet fluid is convected downstream, it is diluted with air and the concentration decreases. Due to differential diffusion effects, $\mathrm{H}_{2}$, diffuses faster than $\mathrm{CO}_{2}$, and the ratio of $\mathrm{H}_{2} / \mathrm{CO}_{2}$ on the centerline of the jet decreases. This is seen as results below the equal diffusivity mixing line in Figure 9. The opposite is seen for large distances from the axis. For obvious reasons, such effects are 


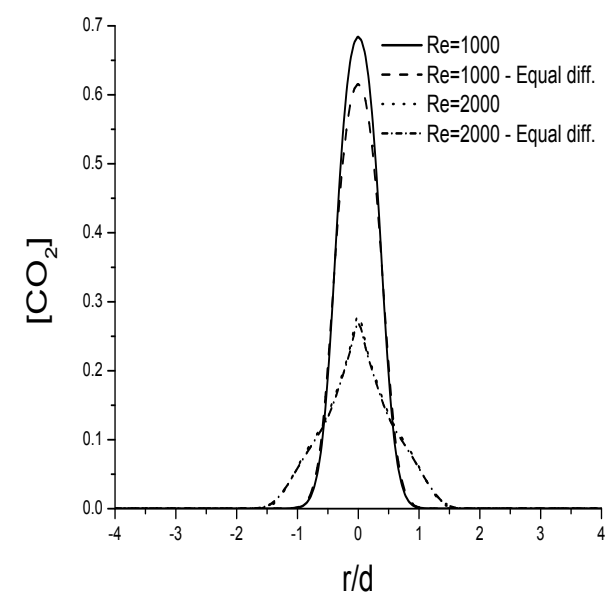

(a)

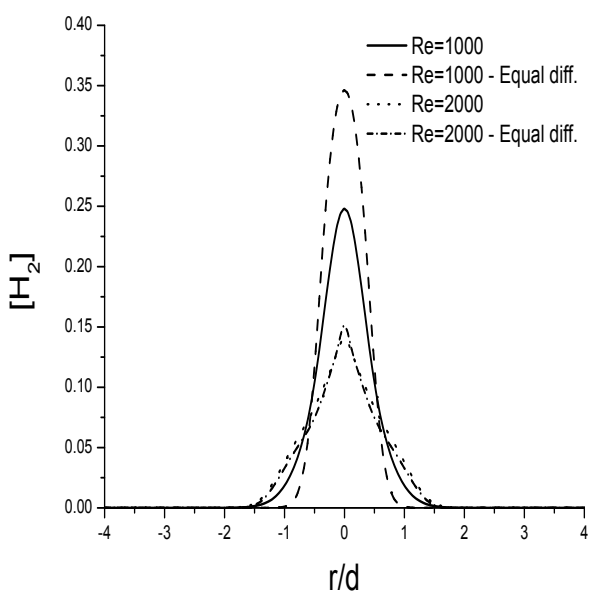

(b)

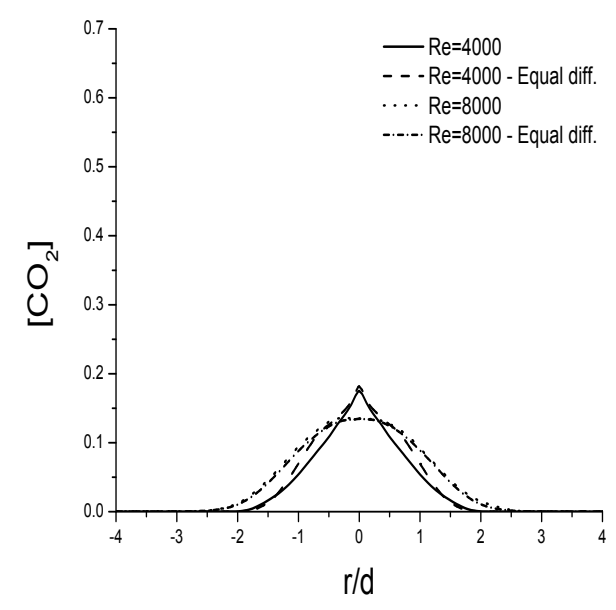

(a)

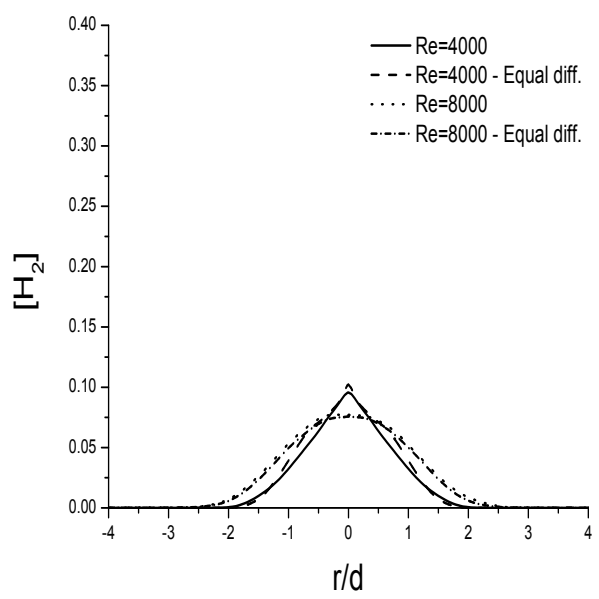

(b)
FIG. 5. Averaged mole fraction results for $R e=1000-2000$ at location $y / d=15$ for (a) $\mathrm{CO}_{2}$ and (b) $\mathrm{H}_{2}$.
FIG. 6. Averaged mole fraction results for $R e=4000-8000$ at location $y / d=15$ for (a) $\mathrm{CO}_{2}$ and (b) $\mathrm{H}_{2}$.

completely missed if equal diffusivity is assumed for all species in the simulations. Overall, a relatively good agreement between the simulation results and the experimental data is observed.

A clearer indication of the behavior of the $\mathrm{H}_{2} / \mathrm{CO}_{2}$ ratio in locations with lower jet fluid concentrations is given in Figure 10. Indeed, as the $\mathrm{H}_{2}$ and $\mathrm{CO}_{2}$ mole fractions tend to zero, it is better to plot the ratio of $\mathrm{CO}_{2} / \mathrm{H}_{2}$ against $\mathrm{CO}_{2}$. In this case, equal diffusivities of $\mathrm{CO}_{2}$ and $\mathrm{H}_{2}$ produce a horizontal line. However, for all Reynolds numbers the averaged results drop below the line of equal mixing for small $\mathrm{CO}_{2}$ concentrations. This occurs near the 


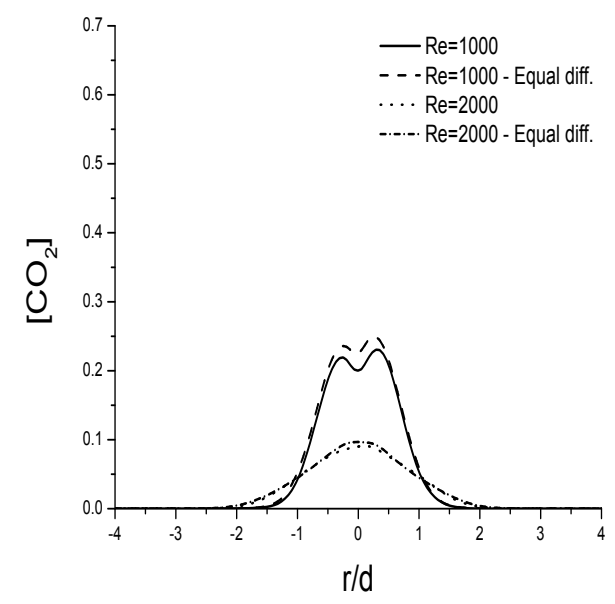

(a)

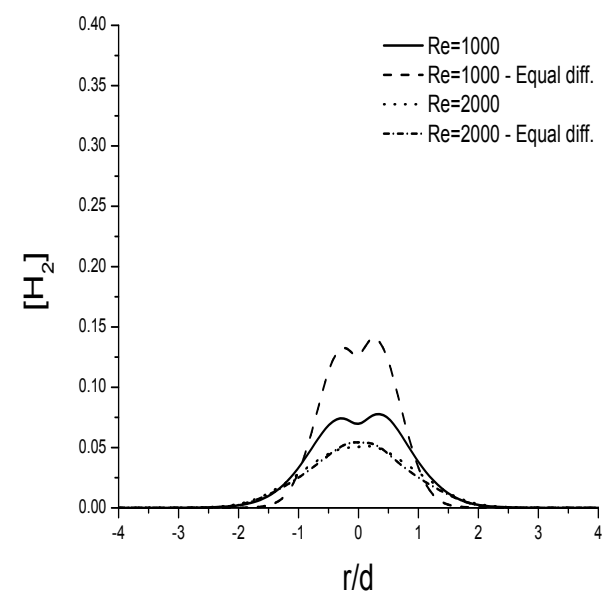

(b)

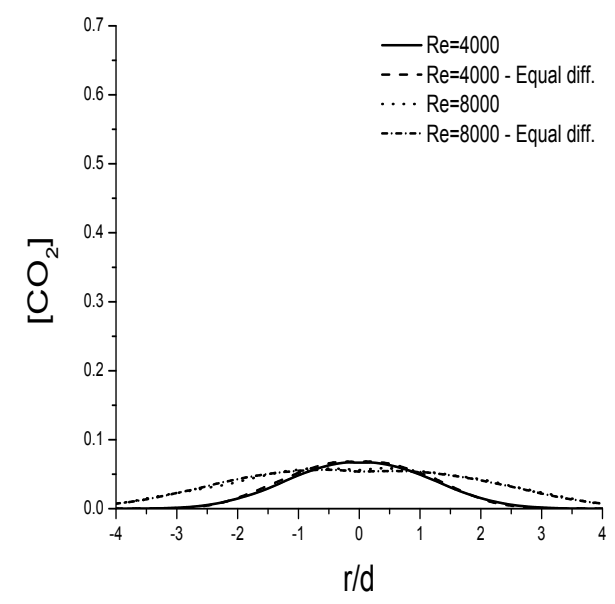

(a)

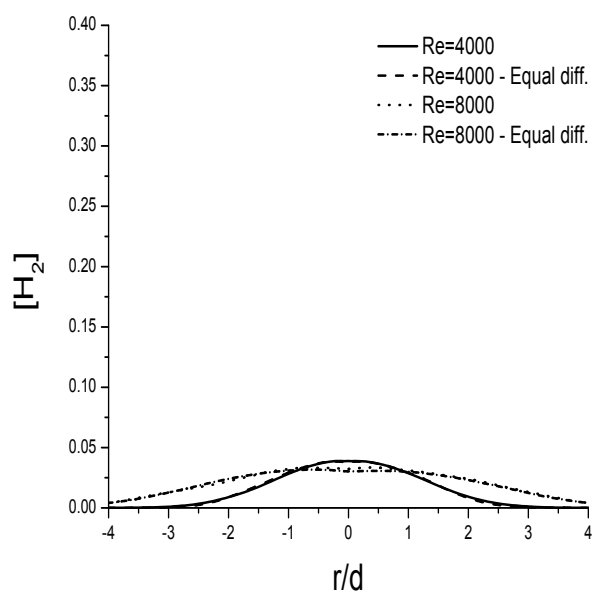

(b)
FIG. 7. Averaged mole fraction results for $R e=1000-2000$ at location $y / d=30$ for (a) $\mathrm{CO}_{2}$ and (b) $\mathrm{H}_{2}$.
FIG. 8. Averaged mole fraction results for $R e=4000-8000$ at location $y / d=30$ for (a) $\mathrm{CO}_{2}$ and (b) $\mathrm{H}_{2}$.

interface of the jet fluid and the co-flowing air, where the $\mathrm{H}_{2}$, being a lighter specie, diffuses outside the jet faster than $\mathrm{CO}_{2}$.

The averaged results of the differential diffusion parameter, $\xi$, for Reynolds numbers $R e=1000-8000$ at locations $y / d=5,15,30$ are presented in Figure 11. Effects of differential diffusion are confirmed for the lower Reynolds number cases $(R e=1000-2000)$ at locations $y / d=15,30$. The faster diffusion of $\mathrm{H}_{2}$ from the core of the jet to the edge creates large negative values of $\xi$ on the centerline $(y / d=0)$. Moving radially outwards, there is more $\mathrm{H}_{2}$ than $\mathrm{CO}_{2}$, which creates positive $\xi$ values with a maximum peak around 


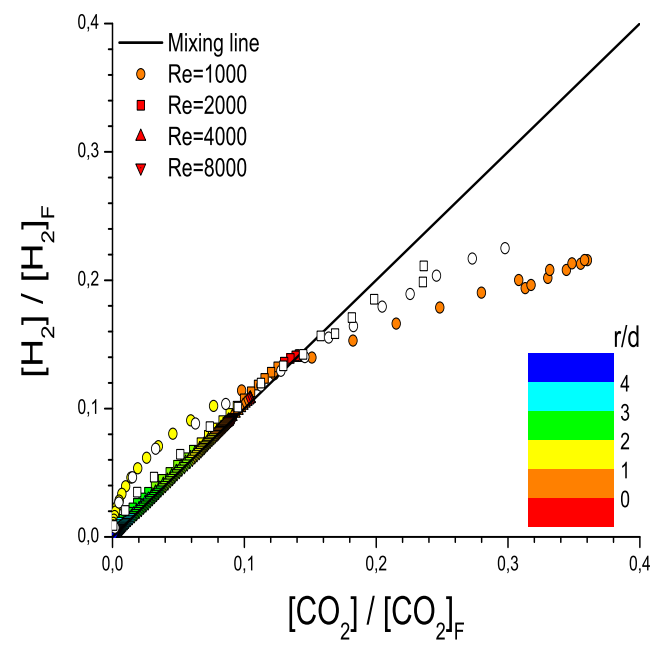

(a)

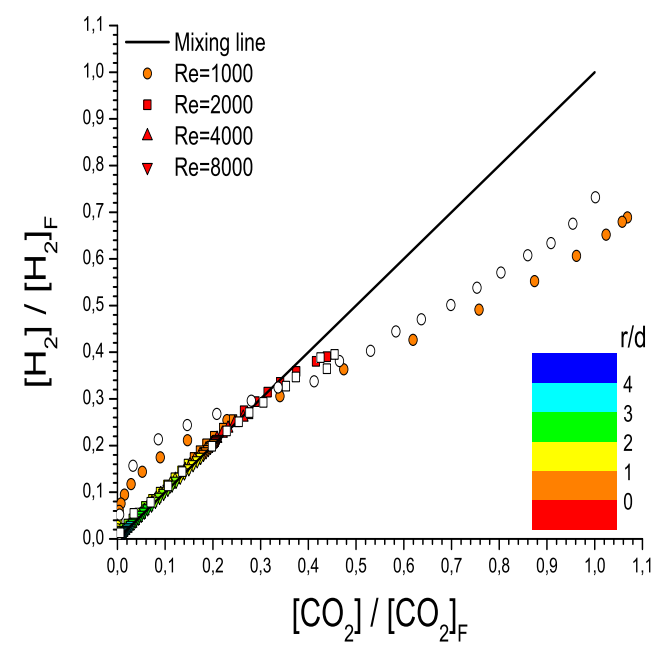

(b)

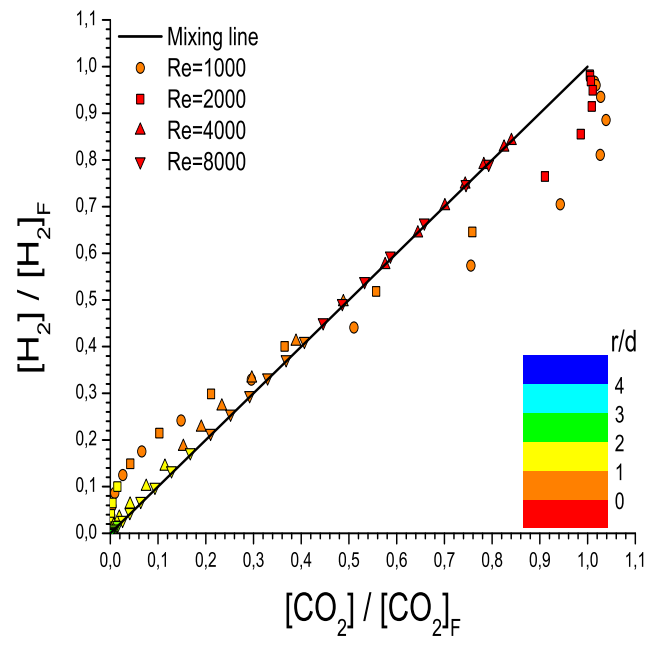

(c)

FIG. 9. Mean mole fraction results of the $\mathrm{H}_{2} / \mathrm{CO}_{2}$ ratio for Reynolds numbers $R e=1000-8000$ at location (a) $y / d=30$, (b) $y / d=15$ and (c) $y / d=5$. White symbols: experimental data.

$y / d=1$. For the higher Reynolds number cases the absolute values of $\xi$ are relatively small. However, close to the inlet (Figure 11(c)), significant differential diffusion effects are present for all Reynolds number cases $(R e=1000-8000)$. 


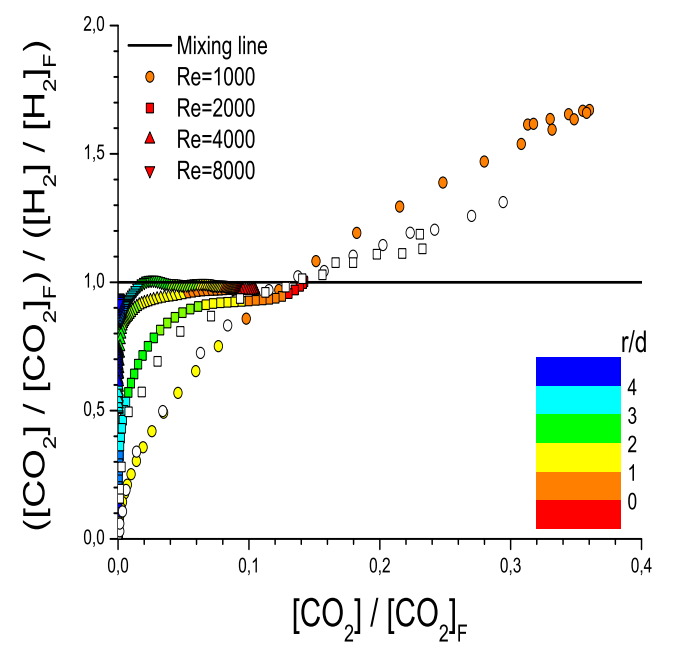

(a)

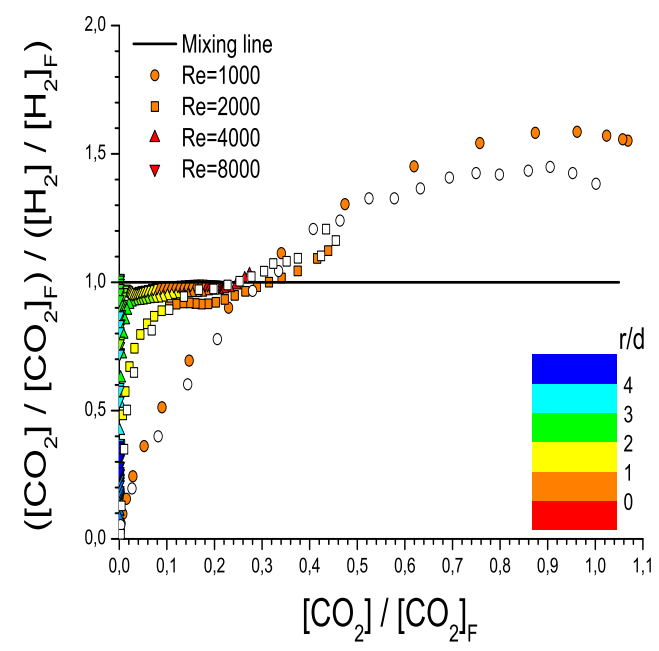

(b)

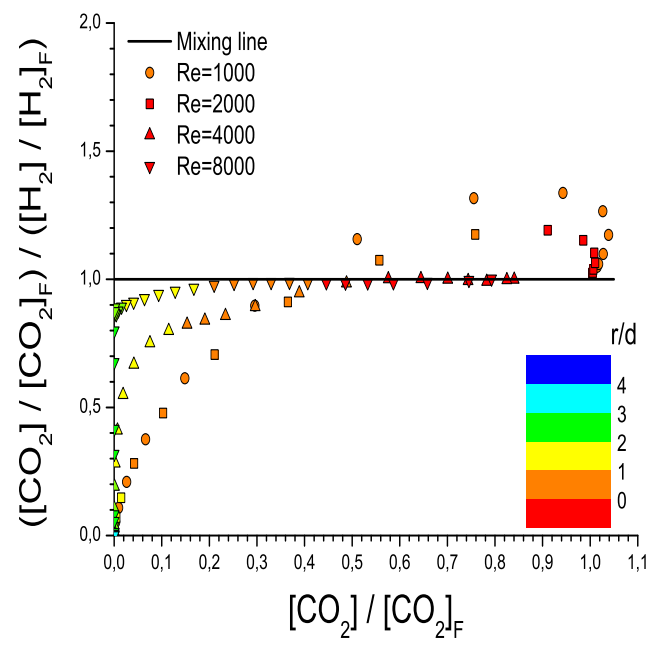

(c)

FIG. 10. Mean mole fraction results of $\mathrm{CO}_{2} / \mathrm{H}_{2}$ vs $\mathrm{CO}_{2}$ for Reynolds numbers $R e=1000-8000$ at location (a) $y / d=30$, (b) $y / d=15$ and (c) $y / d=5$. White symbols: experimental data.

\section{Histograms}

In this section, histograms of the differential diffusion parameter, $\xi$, are presented at various downstream locations and different radial positions. The histograms have been built by monitoring $\xi$ in time at locations $\pm 0.001 \mathrm{~m}$ of the one considered ( $\approx 12000$ samples). For the lower Reynolds number range $(R e=1000-2000)$, histograms only for $R e=2000$ were reported by Smith et al. ${ }^{18}$. For this reason histograms of the differential diffusion parameter, $\xi$, are presented only for this Reynolds number case. 


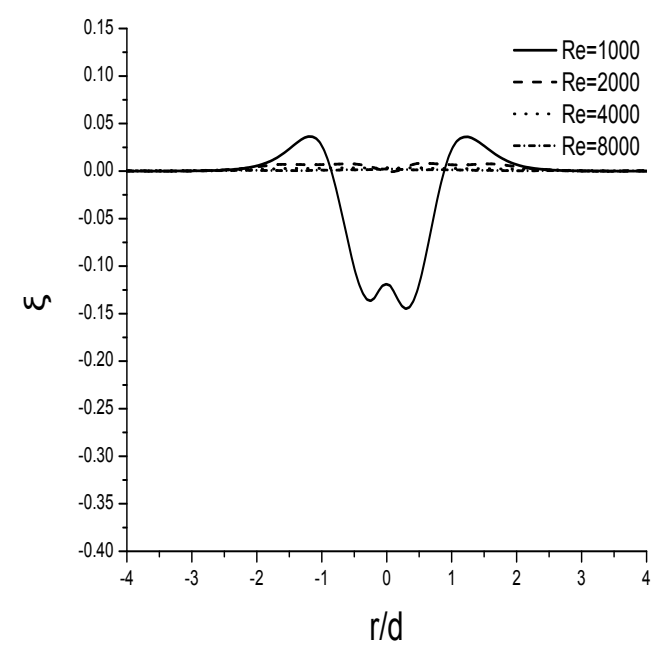

(a)

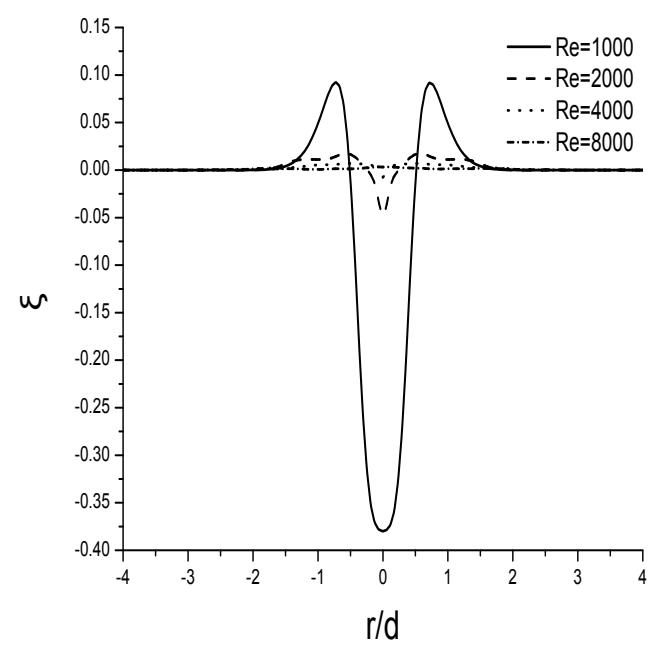

(b)

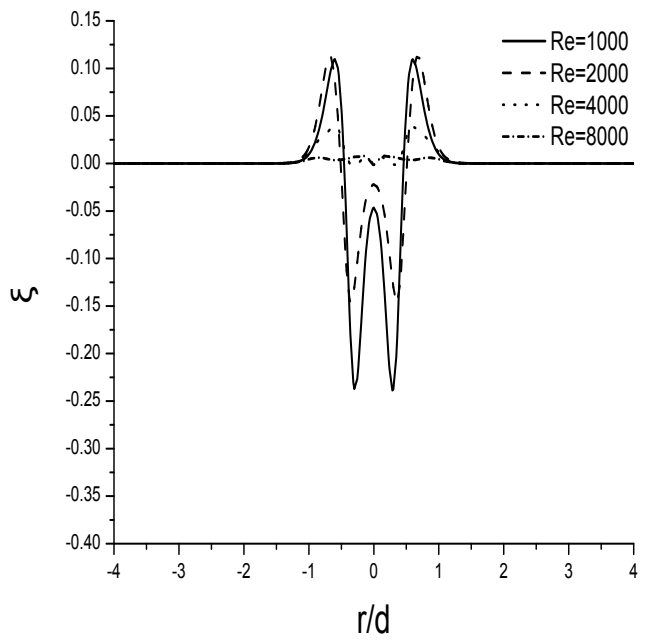

(c)

FIG. 11. Mean differential diffusion parameter, $\xi$ (Eq. 15), for $R e=1000-8000$ at location (a) $y / d=30$, (b) $y / d=15$ and (c) $y / d=5$.

Figure 12 presents histograms for $R e=2000$ at location $y / d=15$ and different radial positions. As the jet is convected downstream, $\mathrm{H}_{2}$, being a much lighter specie, diffuses much faster than $\mathrm{CO}_{2}$ from the centerline to the jet edge, creating this way mostly negative values of $\xi$ on the centerline (Figure 12(a)). Moving radially outwards, at location $r / d=2$, there is more $\mathrm{H}_{2}$ than $\mathrm{CO}_{2}$ and the histogram is now positively skewed (Figure 12(b)). Similar observations apply for the histogram results at location $y / d=30$ shown in Figure 14 . At this location the jet is diluted even more with air and the $\mathrm{H}_{2}$ and $\mathrm{CO}_{2}$ concentrations are smaller than at $y / d=15$, creating a smaller range of $\xi$ values. The histogram on the 
centerline $(r / d=0)$ is centered around zero and shifts to positively skewed with increasing radial distance $(r / d=3)$.

In general, there is a relatively good agreement between the simulation results, shown in Figures 12-14, and the experimental results, shown in Figures 13-15. The only difference observed is that the shape of the simulated histogram on the centerline, $r / d=0$, at location $y / d=15$ is slightly negatively skewed while the experimental ones are symmetric around zero. The shape of the off-axis histograms obtained from the numerical simulations agrees very well with the experimental ones.

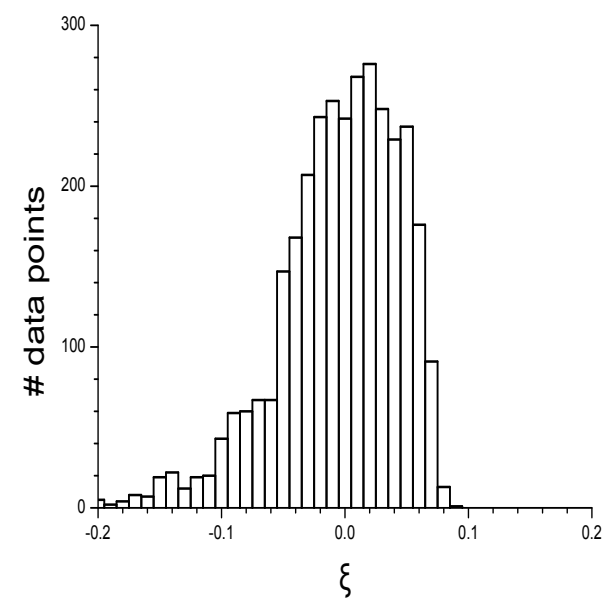

(a)

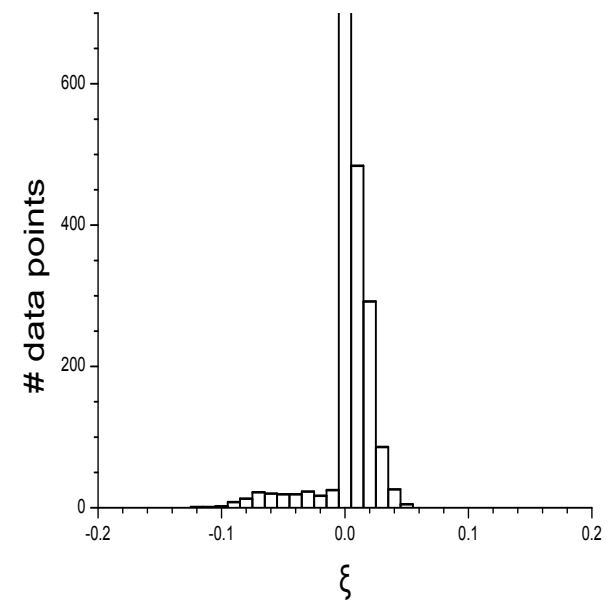

(b)

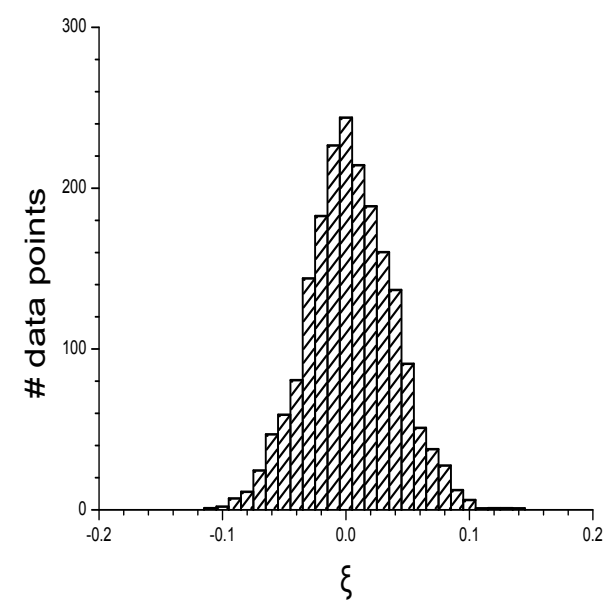

(a)

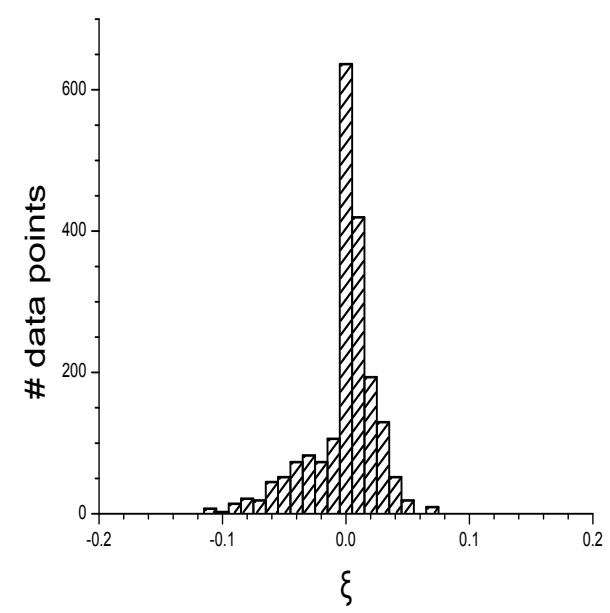

(b)
FIG. 12. Histograms of $\xi$ distribution for $R e=2000$ at location $y / d=15$ for (a) $r / d=$ 0 and (c) $r / d=2$.
FIG. 13. Experimental histograms of $\xi$ distribution for $R e=2000$ at location $y / d=15$ for (a) $r / d=0$ and (c) $r / d=2$. 


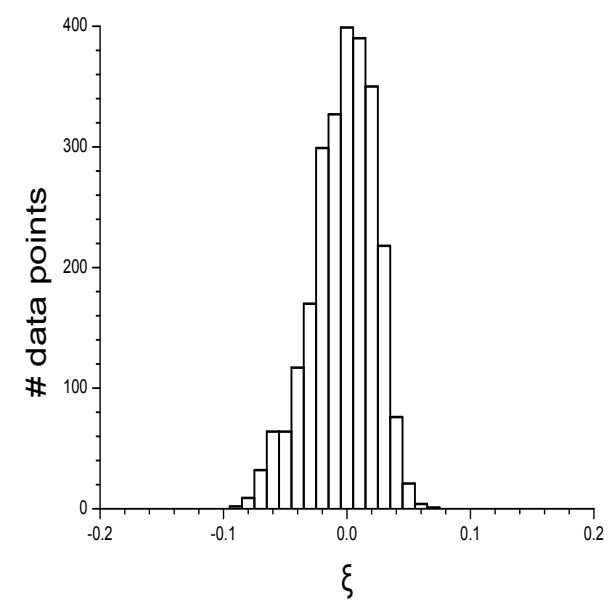

(a)

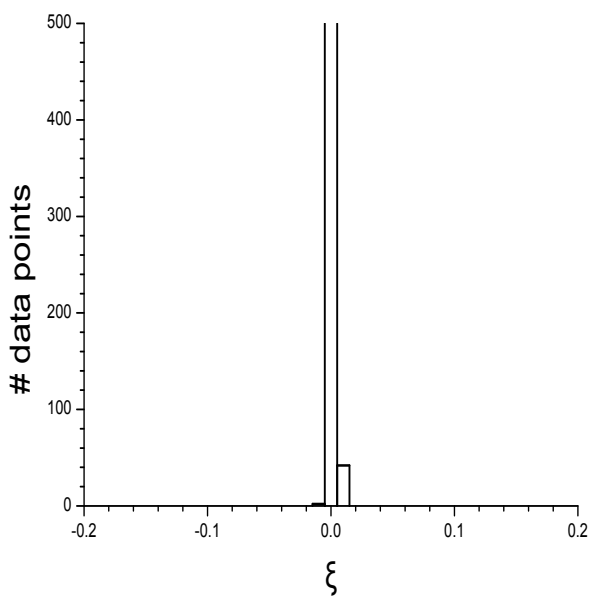

(b)

FIG. 14. Histograms of $\xi$ distribution for $R e=2000$ at location $y / d=30$ for (a) $r / d=$ 0 and $(\mathrm{c}) r / d=3$.

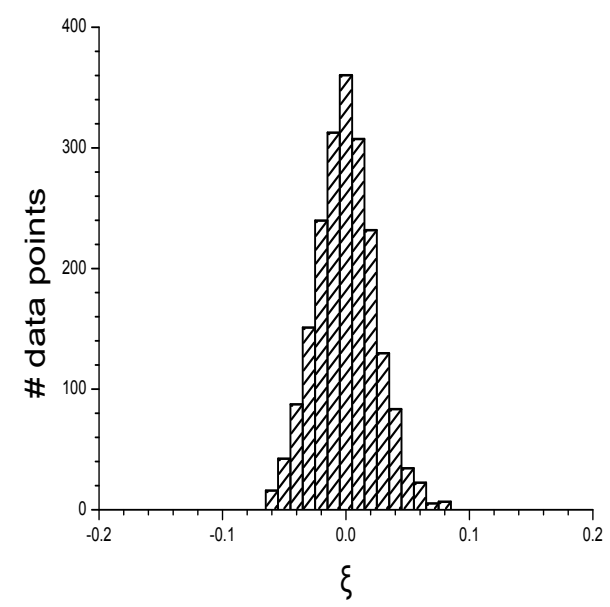

(a)

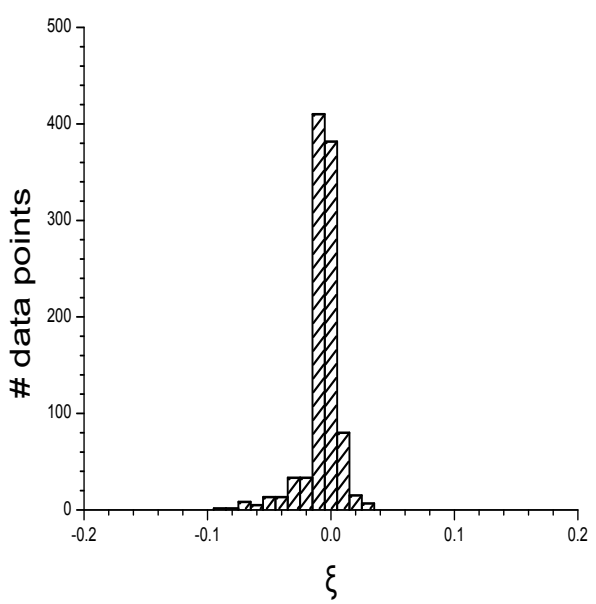

(b)

FIG. 15. Experimental histograms of $\xi$ distribution for $R e=2000$ at location $y / d=30$ for (a) $r / d=0$ and (c) $r / d=3$.

\section{LES RESOLUTION}

The ratio of the turbulent to laminar viscosity, $\mu_{t} / \mu$, is shown in Figure 16. The maximum value of the ratio is less than 2.5, observed in the highest Reynolds number case considered, $R e=8000$. Only in this Reynolds number case, the added sub-grid scale viscosity from the turbulence model is comparable to the molecular viscosity, indicating that the LES grid is fine enough to accurately simulate all the Renolds number cases examined.

The above conclusion is also confirmed by looking at the ratio of grid spacing, $\Delta$, to

Kolmogorov length scale, $\eta_{K}=\left(\frac{\nu^{3}}{\epsilon}\right)^{\frac{1}{4}}$, presented in Figure 17. According to Pope ${ }^{41}$ the 


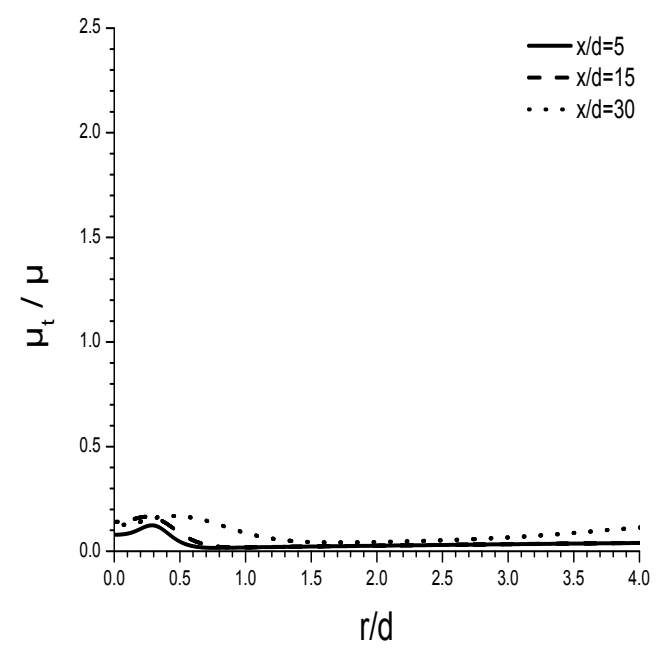

(a)

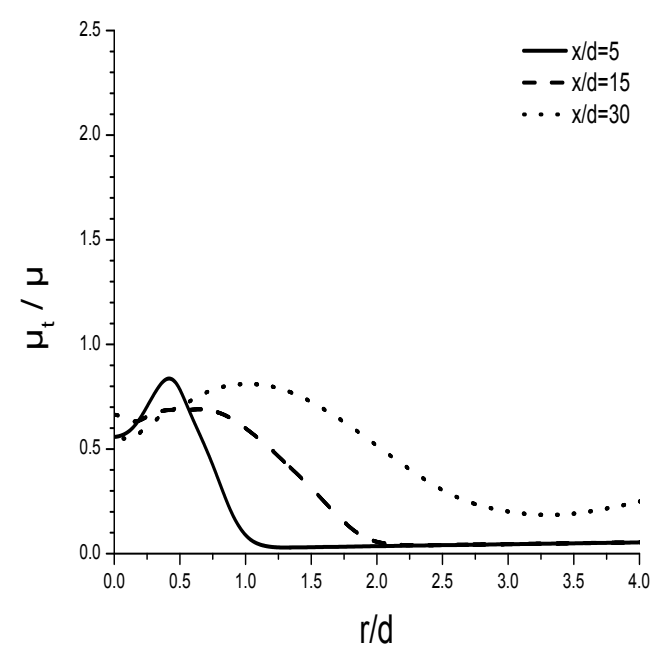

(c)

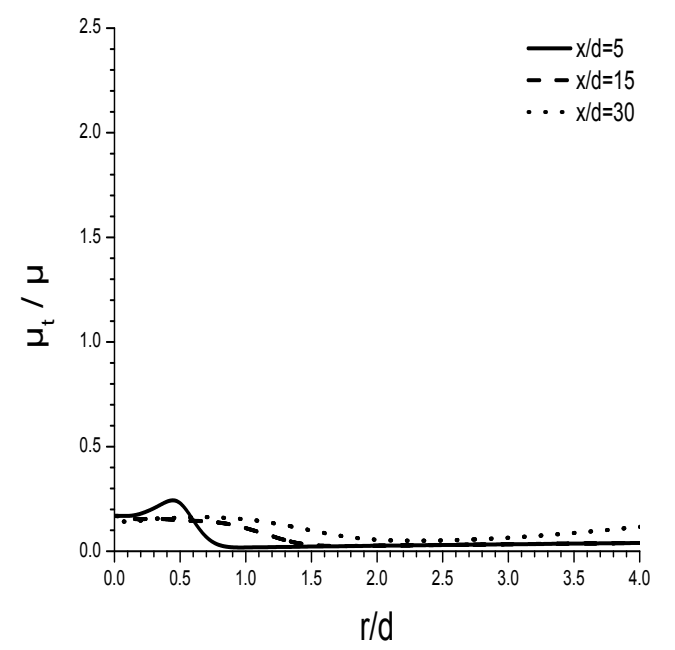

(b)

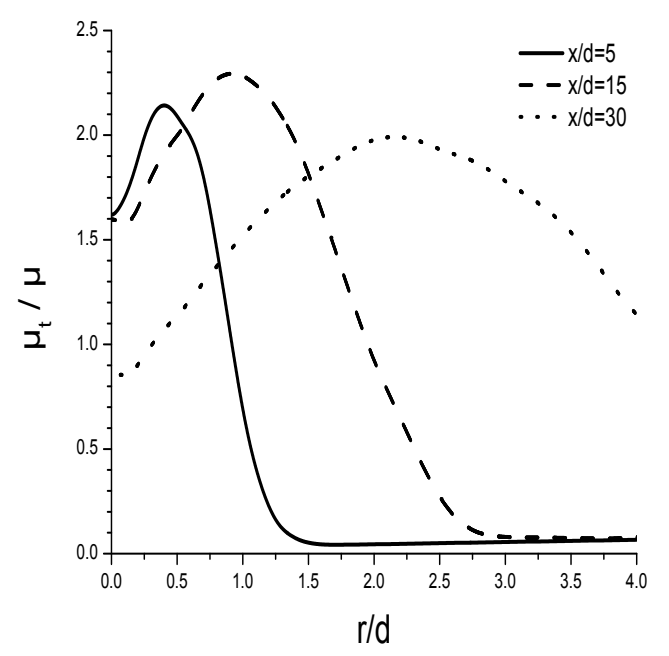

(d)

FIG. 16. Ratio of SGS to laminar viscosity, $\mu_{t} / \mu$, for (a) $R e=1000$, (b) $R e=2000$, (c) $R e=4000$ and (d) $R e=8000$.

demarcation between the inertial and dissipation range for homogeneous isotropic turbulence is located at $k \eta \approx 0.1$ or $\Delta / \eta \approx 32$. Assuming that this criterion remains valid sufficiently far from boundaries, it is used in this work to study the LES resolution. The total dissipation rate is expressed as $\epsilon=2\left(\nu+\nu_{t}\right) \bar{S}_{i j} \bar{S}_{i j}$. For the lower Reynolds number cases $(R e=$ $1000-2000)$ the ratio is less than 6 and goes up to 8 and 10 for the cases with $R e=4000$ and $R e=8000$, respectively. Therefore, the values obtained from the numerical simulations are within the dissipation range, implying a very well resolved LES calculation. 


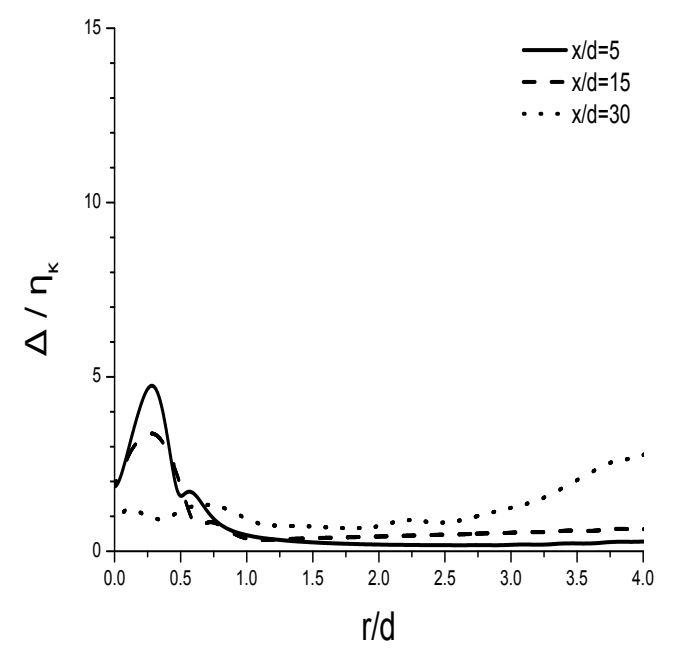

(a)

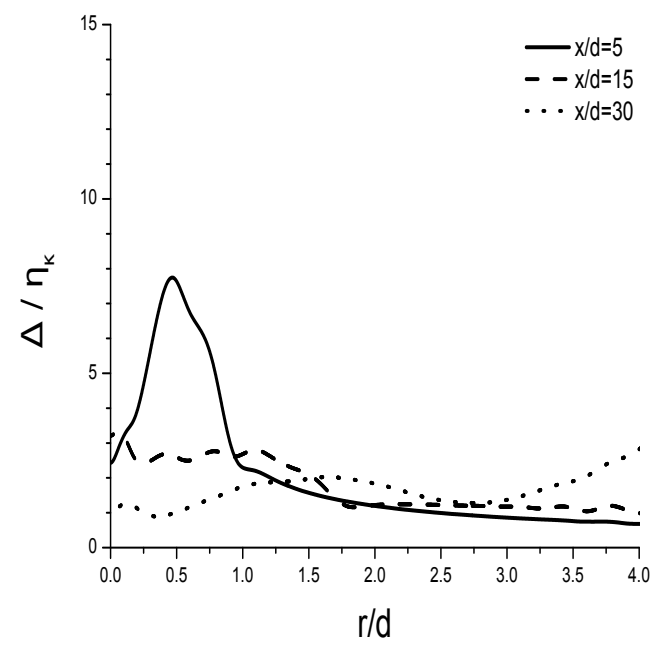

(c)

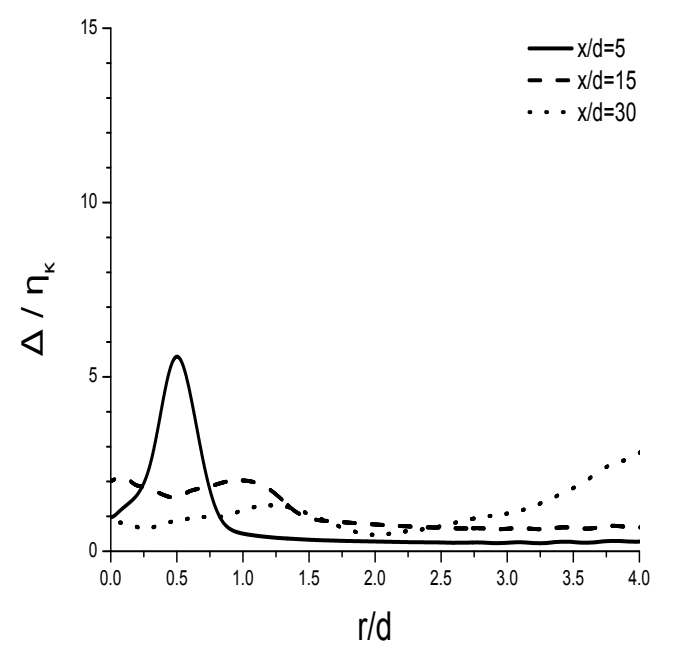

(b)

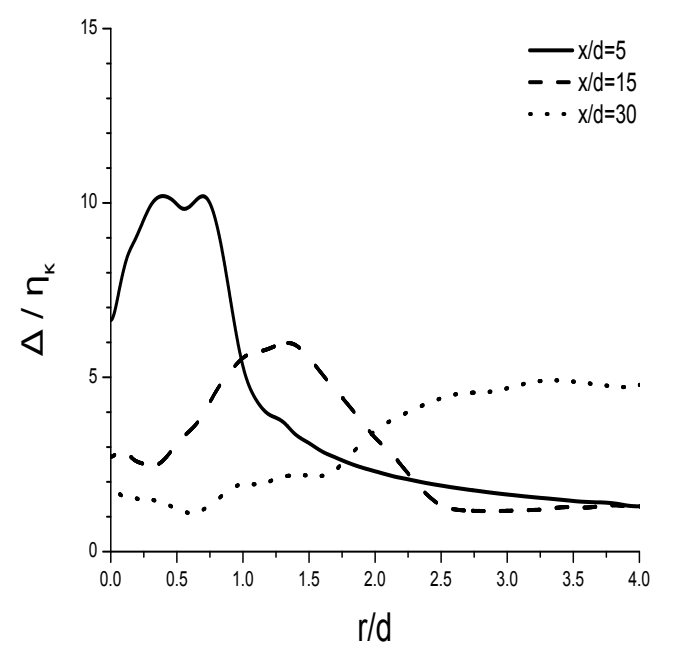

(d)

FIG. 17. Ratio of grid spacing, $\Delta$, to Kolmogorov length scale, $\eta_{K}$, for (a) Re $=1000$, (b) $R e=2000,(\mathrm{c}) R e=4000$ and (d) $R e=8000$.

\section{CONCLUSIONS}

In this study LES results of non-reacting jets of $\mathrm{H}_{2} / \mathrm{CO}_{2}$ mixing with air for Reynolds numbers $R e=1000-8000$ have been presented and compared with the experiments reported by Smith et al. ${ }^{18}$. Overall, there was a good agreement between the simulation results and the experimental data. The amount of experimental data reported was limited (no velocity

field measurements or species concentrations were reported) and the comparison of the experimental data with the simulation results was made up to the degree that this was 
possible. The effects of differential diffusion in the jets have been discussed and analyzed not only in physical space but also with scatter plots and histograms.

At locations far downstream $(y / d>15)$ effects of differential diffusion are visible only for the lower Reynolds number cases $(R e=1000-2000)$. In this case the mean results and scatter plots of the $\mathrm{H}_{2}$ vs $\mathrm{CO}_{2}$ concentrations cluster around the line of equal mixing as the Reynolds number increases. However, close to the inlet $(y / d<10)$ effects of differential diffusion are observed for all the cases examined ( $R e=1000-8000)$, particularly near the edge of the jet. These findings are also confirmed by the mean results of the differential diffusion parameter, $\xi$, with which a quantification of the differential diffusion effects is made in the simulations.

Results obtained assuming equal mass diffusivities for all species reveal that differential diffusion does not have a significant effect in the velocity field. However, differential diffusion strongly affects the $\mathrm{H}_{2}$ concentration on the centerline at all locations examined for $R e=$ 1000, where an over-prediction of more than $40 \%$ is observed. With increasing Reynold number $(R e=2000-8000)$ the differences in the $\mathrm{H}_{2}$ concentrations are negligible.

The analysis on the histograms of the differential diffusion parameter, $\xi$, reveal that at downstream locations, $y / d=15,30$, differential diffusion effects are significant on the centerline, $r / d=0$, and at radial location $r / d=1$, where mostly negative values are obtained, due to the higher diffusivity of $\mathrm{H}_{2}$ from the centerline to the edge of the jet.

The main conclusions of this non-reacting study of differential diffusion can have direct implications to turbulent reacting flows as well. If laminarization of the flow or weakening of turbulent diffusion occurs then differential diffusion effects can be significant even in turbulent flames. The fact that in this case differential diffusion effects were present close to the inlet for moderate to high Reynolds $(\mathrm{Re}=8000)$ is an important indication that differential diffusion should not be neglected in numerical simulations of turbulent reacting flows involving mixtures with vastly different mass diffusivities. Differential diffusion effects can have a significant influence on the stabilization of these flames, typically occurring close to the nozzle. Differential diffusion effects should, therefore, be included in numerical simulations of turbulent reacting flows in order to improve accuracy. 


\section{REFERENCES}

${ }^{1}$ R.W. Bilger, Molecular transport effects in turbulent diffusion flames at moderate Reynolds number, AIAA J., 20, 962-970 (1981)

${ }^{2}$ R.S. Barlow, G.J. Fiechtner, C.D. Carter and J.-Y. Chen, Experiments on the scalar structure of turbulent $\mathrm{CO} / \mathrm{H}_{2} / \mathrm{N}_{2}$ jet flames, Combust. Flame, 120, 549-569 (2000)

${ }^{3}$ W. Meier, R.S. Barlow, Y.-L. Chen and J.-Y. Chen, Raman/Rayleigh/LIF Measurements in a turbulent $\mathrm{CH}_{4} / \mathrm{H}_{2} / \mathrm{N}_{2}$ diffusion flame: Experimental techniques and turbulence chemistry interaction, Combust. Flame, 123, 326-343 (2000)

${ }^{4}$ V. Bergmann and W. Meier and D. Wolff and W. Stricker, Application of spontaneous Raman and Rayleigh scattering and 2D LIF for the characterization of a turbulent $\mathrm{CH}_{4} / \mathrm{H}_{2} / \mathrm{N}_{2}$ jet diffusion flame, Applied Physics B: Lasers and Optics, 66, 489-502 (1997) ${ }^{5}$ A.R. Masri, R.W. Dibble and R.S. Barlow, Chemical kinetic effects in nonpremixed flames of $\mathrm{H}_{2} / \mathrm{CO}_{2}$ fuel, Combust. Flame, 91, 285-309 (1992)

${ }^{6}$ L.L. Smith, R.W. Dibble, L. Talbot, R.S. Barlow and C.D. Caner, Laser Raman scattering measurements of differential diffusion in nonreacting and reacting laminar and turbulent jet flow, 31st Aerospace Science Meeting \& Exhibit, AIAA-93-0804 (1993)

${ }^{7}$ L.L. Smith, R.W. Dibble, L. Talbot, R.S. Barlow and C.D. Carter, Laser Raman Scattering Measurements of Differential Molecular Diffusion in Turbulent NonPremixed Jet Flames of $\mathrm{H}_{2} / \mathrm{CO}_{2}$ fuel, Combust. Flame, 100, 153-160 (1995)

${ }^{8}$ O. Gicque, D. Thévenin and N. Darabiha, Influence of differential diffusion on super equilibrium temperatures in turbulent non-premixed hydrogen/air flames, Flow Turb. Combust., 73, 307-321 (2004)

${ }^{9} \mathrm{R}$. Hilbert and D. Thévenin, Influence of differential diffusion on maximum flame temperature in turbulent nonpremixed hydrogen/air flames, Combust. Flame, 138, 175-187 (2004)

${ }^{10}$ T. Takagi, Z. Xu and M. Komiyama, Preferential Diffusion Effects on the Temperature in Usual and Inverse Diffusion Flames,Combust. Flame, 106, 252-260 (1996)

${ }^{11}$ W. Meier, A.O. Vydorov, V. Bergmann and W. Stricker, Simultaneous Raman/LIF measurements of major species and $\mathrm{NO}$ in turbulent $\mathrm{H}_{2}$ /air diffusion flames, Appl. Phys. B, 63, 79-90 (1996)

${ }^{12}$ R.W. Dibble and M.B. Long, Investigation of differential diffusion in turbulent jet flows 
using planar Rayleigh scattering, Combust. Flame, 143, 644-649 (2005)

${ }^{13}$ J.S. Kim, J. Park, O.B. Kwon, J.H. Jun, S.I. Keel and T.K. Kim, Preferential Diffusion Effects on NO Formation in Methane/Hydrogen-Air Diffusion Flames, Energy \& Fuels, 22, 278-283 (2008)

${ }^{14}$ R.W. Bilger and R.W. Dibble, Differential molecular diffusion effects in turbulent mixing, Combust. Sci. Tehnol., 28, 161-172 (1982)

${ }^{15}$ M.B. Long, S.H. Stårner and R.W. Bilger, Differential diffusion in jets using joint PLIF and Lorenz-Mie imaging, Combust. Sci. Tehnol., 92, 209-224 (1993)

${ }^{16}$ T. Lavertu, W. Pohl, S.J. Gaskin and L. Mydlarski, Punctual and planar measurements of differential diffusion in a turbulent jet, Advances in turbulence X, Proceedings of the 10th European Turbulence Conference, H.I. Andersson \& P.A. Krogstad (Eds.), 235D, p. 1-4. CIMNE, Barcelona 2004 (In Tronheim July 2004)

${ }^{17}$ J.R. Saylor and K R. Sreenivasan, Differential diffusion in low Reynolds number water jets, Combust. Sci. Tehnol., 10, 1135-1146 (1998)

${ }^{18}$ L.L. Smith, R.W. Dibble, L. Talbot, R.S. Barlow and C.D. Carter, Laser Raman scattering measurements of differential molecular diffusion in non-reacting turbulent jets of $\mathrm{H}_{2} / \mathrm{CO}_{2}$ mixing with air, Phys. Fluids, 7, 1455-1466 (1995)

${ }^{19}$ A.R. Kerstein, M.A. Cremer and P.A. McMurtry, Scaling properties of differential molecular diffusion effects in turbulence, Phys. Fluids, 7, 1999-2008 (1995)

${ }^{20}$ M. Ulitsky, T. Vaithianathan and L.R. Collins, A spectral study of differential diffusion of passive scalars in isotropic turbulence, J. Fluid Mech., 460, 1-38 (2002)

${ }^{21}$ P.K. Yeung and S.B. Pope, Differential diffusion of passive scalars in isotropic turbulence, Phys. Fluids A, 5, 2467-2478 (1993)

${ }^{22} \mathrm{P}$. K. Yeung, Multi-scalar triadic interactions in differential diffusion with and without mean scalar gradients, J. Fluid Mech., 321, 235-278 (1996)

${ }^{23}$ A. Kronenburg and R.W. Bilger, Modelling of differential diffusion effects in non-premixed non-reacting turbulent flow, Phys. Fluids, 9, 1435-1447 (1997)

${ }^{24}$ V. Nilsen and G. Kosály, Differentially diffusing scalars in turbulence, Phys. Fluids, 9, 3386-3397 (1997))

${ }^{25}$ P.K. Yeung, Correlations and conditional statistics in differential diffusion: Scalars with uniform mean gradients, Phys. Fluids, 10, 2621-2635 (1998)

${ }^{26}$ R.O. Fox, The Lagrangian spectral relaxation model for differential diffusion in homoge- 
neous turbulence, Phys. Fluids, 11, 1550-1571 (1999)

${ }^{27}$ P.K. Yeung, M.C. Sykes and P. Vedula, Direct numerical simulation of differential diffusion with Schmidt numbers up to 4.0, Phys. Fluids, 12, 1601-1604 (2000)

${ }^{28}$ F.A. Jaberi, R.S. Miller, F. Mashayek and P. Givi, Differential diffusion in binary scalar mixing and reaction, Combust. Flame, 109, 561-577 (1997)

${ }^{29}$ G. Maragkos, P. Rauwoens and B. Merci, Application of FDS and FireFOAM in large eddy simulation of a turbulent buoyant helium plume, Combust. Sci. Technol., 184, 1108-1120 (2012)

${ }^{30}$ G. Maragkos, P. Rauwoens, Y. Wang and B. Merci, Large eddy simulations of the flow in the near-field region of a turbulent buoyant helium plume, Flow Turb. Combust., 90, $511-543(2013)$

${ }^{31}$ G. Maragkos, P. Rauwoens and B. Merci, A new methodology to incorporate differential diffusion in CFD simulations of reactive flows, Combust. Flame, 160, 1903-1905 (2013)

${ }^{32}$ J. Smagorinsky, General circulation experiments with the primitive equations. I. The basic experiment, Mon. Weather Rev., 91, 99-164 (1963)

${ }^{33}$ T. Poinsot and D. Veynante, Theoretical and Numerical combustion, Edwards (2001)

${ }^{34}$ E. Garnier, N. Adams and P. Sagaut, Large Eddy Simulation for Compressible Flows, Springer (2009)

${ }^{35}$ X. Zhou, K.H. Luo and J.J.R. Williams, Large eddy simulation of turbulent forced plume, Eur. J. Mech. B Fluids, 20, 233-254 (2001)

${ }^{36}$ E. Giacomazzi, F. R. Picchia and N. Arcidiacono, A review of chemical diffusion: Criticism and limits of simplified methods for diffusion coefficient calculation, Combust. Theory Model., 12, 135-158 (2007)

${ }^{37}$ T.P. Coffee and J.M. Heimerl, Transport algorithms for premixed, laminar steady-state flames, Combust. Flame, 43, 273-289 (1981)

${ }^{38}$ A. Ern and V. Giovangigli, Multicomponent transport algorithms, Springer (1994)

${ }^{39}$ A. Menon and M. Rizk, Large-eddy simulations of forced three-dimensional impinging jets, Int. J. Comput. Fluid Dyn., 7, 275-289 (1996)

${ }^{40}$ J.C. Sutherland, P.J. Smith and J.H. Chen, Quantification of differential diffusion in nonpremixed systems, Combust. Theory Model., 9, 365-383 (2005)

${ }^{41}$ S.B. Pope, Turbulent Flows, Cambridge University Press (2000) 